\title{
Is It Really Impossible To Divide By Zero?
}

\section{Hiroshi Okumura}

Ph.D, Maebashi Institute of Technology (retired), Thailand

Submission: March 26, 2018; Published: May 22, 2018

*Corresponding author: Hiroshi Okumura, Ph.D. Maebashi Institute of Technology (retired), Mueang District KhonKaen 40000, Thailand, Tel: +819025457254; Email: okumura.hirosi@palette.plala.or.jp

\section{Abstract}

It has been said that to define to divide by zero is impossible. But recent attempts show that it can be done very easily, which we would like to show below.

Keywords: Divide by zero; Impossible; Satisfying; Natural extension; Ordinary fraction; Real number; Amazing phenomena; Origin; Perpendicularly; Intersecting curves; Tangents; Intersection; Two curves; Infinity; Orthogonal; Slope; Horizontal line; Fixed radius; Initial point; Graph passes; Circle.

\section{Mini Review}

\section{Definition}

Let us consider a function $F: \mathrm{R} \times \mathrm{R} \rightarrow \mathrm{R}$ satisfying

$$
\left\{\begin{array}{l}
F(a, b)=\frac{a}{b} i f b \neq 0, \\
F(a, b) F(c, d)=F(a c, b d)
\end{array} .\right.
$$

This is a natural extension of the ordinary fraction $a / b$.

While,

$$
\begin{gathered}
F(a, 0)=\frac{2}{2} F(a, 0)=F(2,2) F(a, 0)=F(2 a, 0) \\
=F(2,1) F(a, 0)=\frac{2}{1} F(a, 0)=2 F(a, 0)
\end{gathered}
$$

implies $F(a, 0)=2 F(a, 0$ Therefore $F(a, 0)=($ for any real number $a$ [1]. The fact shows that we have no choice but to define $a / 0=0$ for any real number $a$. Hence, we define

$$
\frac{a}{0}=0
$$

\section{For any real number $a$.}

Notice that we also get $0 / 0=0$ by the definition [1-4]. This simple discussion was made by Sin-Ei Takahashi, an emeritus professor at Yamagata University. As you see the definition of the division by zero is very easy, but we have to notice that $1 / 0$ is not the inverse of 0 , i.e.,

$$
0 \times \frac{1}{0}=0 \times 0=0 .
$$

The same definition was already given by Brahmagupta.

\section{What can be seen from the definition}

The definition (1) brings us several amazing phenomena. A typical thing is that most things we have been thinking as infinity without paying attention are exactly 0.For example, for the function $y=1 / x, x=0$ implies $y=0$, i.e., its graph passes through the origin $(0,0)$.

If the two lines $a_{i} x+b_{i} y+c_{i}=0(i=1,2)$ are not parallel, they meet in the point

$$
\left(\frac{b_{1} c_{2}-b_{2} c_{1}}{a_{1} b_{2}-a_{2} b_{1}}, \frac{a_{2} c_{1}-a_{1} c_{2}}{a_{1} b_{2}-a_{2} b_{1}}\right) .
$$

If they are parallel, i.e., $a_{1} b_{2}-a_{2} b_{1}=0$, the definition (1) shows that they meet in the origin $(0,0)$. The other typical thing is that the two perpendicularly intersecting curves can be considered as they touch. Because we get $\tan 90^{\circ}=0$ by the definition (1). Therefore if two curves intersect perpendicularly, the slopes of the two tangents at the point of intersection are the same, i.e., we can still consider that the two curves touch at the point [5-8].

Let us consider a circle $C$ of fixed radius $r$ with center $P$ on a half line with initial point $O$ (Figure 1). Let $t$ be one of the tangents of $C$ from $O$ and let $\theta$ be the angle between $l$ and $t$. Then we can easily get

$$
|O P|=\frac{r}{\sin \theta}
$$



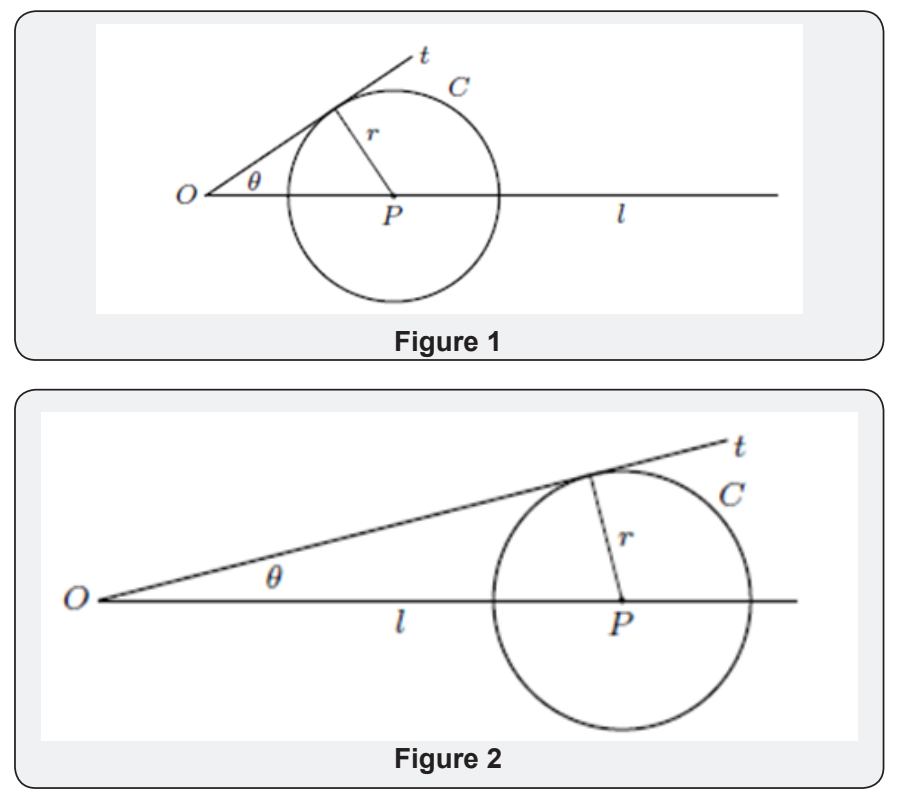

We now consider the angle $\theta$ becomes smaller and smaller. Then $P$ gets further away from $O$ (Figure2). In the case $\theta=0$, the lines $l$ and $t$ coincide. Then one may think that the circle $C$ has moved away into point at infinity (this is not an exact expression though). But the definition (1) implies

$$
|O P|=\frac{r}{\sin 0^{0}}=\frac{r}{0}=0
$$

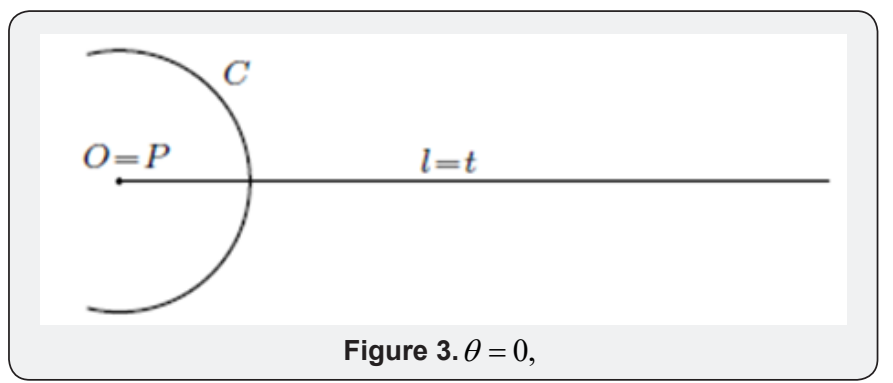

Figure 3. $\theta=0$,
Hence the point $P$ coincides with $O$ (Figure 3). The line $t$ touches $C$ in the case $\theta>0$, but it is orthogonal to $C$ in the case $\theta=0$. But we can still consider that it touches $C$ because the tangent at the point of intersection has slope $\tan 90^{\circ}=0$ by the definition (1) if $l$ is a horizontal line.

\section{Conclusion}

Mathematics is made upon the postulates. Any postulate should be taken into consideration, if it gives reasonable conclusions with new insights. The research of the division by zero was established by Saburou Saitoh [8], an emeritus professor at Gunma University, four years ago. Since the foundation of this topics are already made [1-8], it seems that the research is entering next stage as experts consider the division by zero in each of the special fields of Science.

\section{References}

1. Kuroda M, Michiwaki H, Saitoh S, Yamane M (2014) New meanings of the division by zero and interpretations on $100=0=0$ and $0=0=0$. Int J Appl Math 27(2): 191-198.

2. Matsuura T, Michiwaki H, Saitoh S (2017) $\log 0=\log 1=0$ and applications. Differential and Difference Equations with Applications. Springer Proceedings in Mathematics \& Statistics.

3. Matsuura T, Saitoh S (2016) Matrices and Division by zero z/0 $=0$. Adv Linear Algebra \& Matrix Theory 6: 51-58.

4. Michiwaki H, Okumura H, Saitoh S (2017) Division by Zero z/0 = 0 in Euclidean Spaces. Int J Math Comput 28(1) (2017) 1-16.

5. Michiwaki H, Saitoh S, Yamada M (2016) Reality of the Division by Zero $\mathrm{z}=0=0$. Int J Appl Phys Math 6(1): 1-8.

6. Okumura H, Saitoh S (2018) Remarks for the Twin Circles of Archimedes in a Skewed Arbelos by Okumura and Watanabe. Forum Geom 18: 97-100.

7. Okumura H, Saitoh S, Matsuura T (2017) Relations of 0 and 1. J Tech Social Science 1(1): 70-77.

8. Pinelas S, Saitoh S (2016) Division by zero calculus and differential equations, Differential and Difference Equations with Applications. Springer Proceedings in Mathematics \& Statistics.

\section{Your next submission with Juniper Publishers} will reach you the below assets

- Quality Editorial service

- Swift Peer Review

- Reprints availability

- E-prints Service

- Manuscript Podcast for convenient understanding

- Global attainment for your research

- Manuscript accessibility in different formats

( Pdf, E-pub, Full Text, Audio)

- Unceasing customer service

Track the below URL for one-step submission https://juniperpublishers.com/online-submission.php 